declared, Amye Leong: None declared, Elyse Reyes: None declared, Richard Street: None declared, Maria Suarez-Almazor : None declared, Guy Eakin: None declared, Laura Marrow: None declared, Charity Morgan: None declared, Brennda Caro: None declared, Jeffrey Sloan: None declared, Bochra Jandali: None declared, Salvador Garcia: None declared, Jennifer Grossman: None declared, Kevin Winthrop Consultant for: Gilead, Galapagos, Eli Lilly and Company, Abbvie, Pfizer, GSK, Laura Trupin: None declared, Maria Dall'Era Grant/research support from: University has received funds to serve as a site on this clinical study, Consultant for: On Data Monitoring Committee for Janssen, Biogen, and Genentech; on Steering Committee for EMD Serono., Alexa Meara: None declared, Tara Rizvi: None declared, Winn Chatham: None declared, Jinoos Yazdany Grant/research support from: Pfizer, Consultant for: AstraZeneca DOI: 10.1136/annrheumdis-2019-eular.7938

\section{THU0652 THE ECONOMIC BURDEN OF ANCA-ASSOCIATED VASCULITIS IN GERMANY - A CLAIMS DATA STUDY}

Philip Spearpoint $^{1}$, Dieter Götte ${ }^{2}$, Angelika Deichmann ${ }^{3}$, Marc Wengler $^{3}$, Matthias Schoenermark ${ }^{3}$, Peter Rutherford ${ }^{2}{ }^{1}$ Viforpharma, Global PricingandMarket Access, Glattbrugg, Switzerland; ${ }^{2}$ Viforpharma, Global Medical Affairs, Glattbrugg, Switzerland; ${ }^{3}$ SKC Beratungsgesellschaft, Hannover, Germany

Background: ANCA-associated vasculitis AAV is a rare systemic disease, characterized by recurrent episodes of systemic inflammation. It is a severe disease associated with hospitalization, risk of renal failure and a therapy inducing serious side effects. The economic impact of AAV to the German health care system is currently not well understood.

Objectives: The aim of this study was to better understand and quantify the economic burden of AAV in Germany. Therefore, selected aspects, such as prevalence and incidence, frequency of hospitalization, frequency of intensive care unit (ICU) stays and treatments costs, were systematically assessed in a claims data study.

Methods: Longitudinal data from years 2013 to 2016, provided by German statutory health insurance (SHI) companies from the InGef database have been analyzed representing an age- and gender stratified cohort of approx. 4 million insured persons representative for the German population.

Results: Prevalence and incidence data show that, in accordance with the previously published literature $(1,2)$, Granulomatosis with Polyangiitis (GPA) was more frequent than Microscopic Polyangiitis (MPA). On average, a combined prevalence of 256: 1000000 (210: 1000000 for GPA and 46: 1000000 for MPA) was identified within the data set over the observed time period of 4 years (2013-2016). Incidence rates were found to be $46: 1000000$ (34: 1000000 for GPA and 13 : 1 000000 for MPA) within the same time period. Over the observed time period, prevalence and incidence rates remained stable.

The majority of AAV (GPA and MPA) diagnoses were made in hospitals $(61 \%)$, another $24 \%$ were diagnosed in the outpatient sector and $15 \%$ were diagnosed in both within one quarter. In total, $97 \%$ of newly diagnosed patients (GPA and MPA) were hospitalized within 4 years post diagnosis. Especially during the induction period (quarter of diagnosis and the following 2 quarters) $91 \%$ (GPA) to $95 \%$ (MPA) of the patients were hospitalized. Of these patients, approx. $60 \%$ were hospitalized due to GPA and MPA disease, showing the high rate of severe co-morbidities. Patients diagnosed with GPA and MPA were frequently treated at ICUs (in average 1 stay per quarter); in particular severe infections and renal involvements increased the likelihood of ICU stays.

Treatment costs were highest during the induction period; within this period hospitalization represented the largest cost factor. Severe kidney disease, which occurred in $11,6 \%$ of GPA and $24,3 \%$ of MPA patients, induced total costs ranging between $131.521 €$ (GPA) to $145.472 €$ (MPA) over four years post diagnosis, with the induction period being most expensive (approx. 58.826 $€$ to $50.339 €$ for GPA and MPA during the induction period). In the following years total treatment and hospital costs decreased, however remained high.

Conclusion: AAV represents an underestimated financial burden to the German healthcare system, especially during induction therapy. The high level of hospitalizations amongst AAV patients also represents a high usage of healthcare resources. Thus, AAV represents an underestimated cost factor for the German health care system, and better treatment options are desperately needed.

\section{REFERENCES:}

1. Herlyn K, Hellmich B, Gross WL, Reinhold-Keller E. Stable incidence of systemic vasculitides in schleswig-holstein, Germany. Dtsch Arztebl Int. 2008;105(19):355-61.
2. Reinhold-Keller E, Herlyn K, Wagner-Bastmeyer R, Gross WL. Stable incidence of primary systemic vasculitides over five years: results from the German vasculitis register. Arthritis Rheum. 2005;53(1):93-9.

Disclosure of Interests: Philip Spearpoint Consultant for: Multiple pharmaceutical companies as a Management Consultant (employee fo Huron Consulting Group), Employee of: Viforpharma, Dieter Götte Employee of: Vifor Pharma, Angelika Deichmann Consultant for: Employee of SKC Beratungsgesellschaft, Hannover, Paid instructor for: Medical Writer at SKC Beratungsgesellschaft, Marc Wengler Consultant for: Medical Writer, SKC Beratungsgesellschaft, Matthias Schoenermark Consultant for: CEO SKC Beratungsgesellschaft, Hannover, Paid instructor for: CEO SKC Beratungsgesellschaft, Peter Rutherford Employee of: Vifor Pharma DOI: 10.1136/annrheumdis-2019-eular.2989

\section{THU0653 SOCIOECONOMIC ANALYSIS OF GOLIMUMAB TREATMENT IN PATIENTS WITH RA, PSA, AND AS - NON-INTERVENTIONAL STUDY GO-NICE}

Klaus Krueger ${ }^{1}$, Gerd Rüdiger Burmester ${ }^{2}$, Siegfried Wassenberg ${ }^{3}$, Astrid Thiele ${ }^{4}$, Matthias Thomas ${ }^{5} .{ }^{1}$ Rheumatologisches Praxiszentrum St. Bonifatius, München, Germany, ${ }^{2}$ Charité- Universitätsmedizin, Department of Rheumatology and Clinical Immunology, Berlin, Germany; ${ }^{3}$ Rheumazentrum Ratingen, Ratingen, Germany; ${ }^{4}$ Krankenhaus St. Josef, Wuppertal, Germany, ${ }^{5} \mathrm{MSD}$ Sharp and Dohme GmbH, Medical Affairs, Haar, Germany

Background: Rheumatic diseases are associated with pain, loss of functionality, fatigue, hospitalization, sick leave, and work disability. This results in high economic burden for patients and society.

Objectives: Golimumab (GLM) is an effective but costly treatment option for patients (pts.) with moderate to severe, active rheumatic diseases. The aim of this analysis of the GO-NICE study was to investigate the direct and indirect costs of healthcare utilization and sick leave after starting a treatment with GLM.

Methods: Data of outpatients collected in the non-observational study GONICE in 1,483 pts. with RA $(n=474)$, PsA $(n=501)$, and AS $(n=483)$ in 158 sites (2010-2015) in Germany were analysed. Details on the study design, pts. characteristics, the clinical and patient-reported outcomes, and safety data have been reported earlier $[1,2]$.

Direct medical and indirect costs per patient and year were calculated for consultations, physiotherapy, massages, hospitalisations and inpatient rehabilitation, medication (DMARDs, Glucocorticoids, NSAIDs, and biologics) as well as sick leave days. Findings were shown for RA-, PsA- and AS-pts. and categorised by biological-naïve pts. and pts. with a pre-treatment with a biologic. The 6-month periods prior baseline (BL)/start of a GLM therapy vs. month 24 (M24) were compared.

For this calculation the standardized evaluation rates were used (Bock et al. (2015), AG MEG of the DGSMP (2005). Costs for prescribed and documented medication were calculated by the mean cost per defined daily dose (based 2010-2015). Indirect costs were estimated through the human capital approach (HCA)

Results: Data of 758 biologic-naïve pts. ( $n=265$ RA, 247 PsA and 246 AS) and 694 pts. with biologics as pre-therapy ( $n=208$ RA, 252 PsA and 234 AS) were included in the analysis.

Direct medical costs (excl. medication) decreased in all 6 groups, min. $765 €$ (PsA pre-treatment group) and max. 2,426€ (AS pre-treatment) as well as the costs due to work disability/absenteeism, min. $855 €$ (PsA pre-treatment) and max. $2.564 €$ (RA pre-treatment, table).

Total costs in biological-naïve pts. increased due to the additional expense of the biologic agent.

Absolute changes in costs totalled 15,665€ (RA-, table), 15,799€ (PsA-) and $14,764 €$ (AS-patients) per patient and year when comparing the BL vs. M24 periods.

Total savings of $6,289 €$ (RA-, table), 2,617€ (PsA-), and 5,555€ (AS patients) per patient and year were generated in the group of biologicpre-treated patients.

\begin{tabular}{lcccccc}
\hline & \multicolumn{3}{c}{ RA pts. biologic-naïve $(\mathrm{n}=265)$} & \multicolumn{3}{c}{$\begin{array}{c}\text { RA pts. with biologics as pre- } \\
\text { treatment }(\mathrm{n}=208)\end{array}$} \\
\hline & Baseline & $\begin{array}{c}\text { Month } \\
24\end{array}$ & Changes & Baseline & $\begin{array}{c}\text { Month } \\
24\end{array}$ & Changes \\
\hline Consultation fees/€ & 354 & 168 & -186 & 369 & 178 & -191 \\
$\begin{array}{l}\text { Physiotherapy, massages } \\
\text { etc./€ }\end{array}$ & 162 & 59 & -103 & 144 & 91 & -53 \\
$\begin{array}{l}\text { Hospitalisation/€ } \\
\text { Rehabilitation measures/ }\end{array}$ & 939 & 99 & -840 & 1,163 & 423 & -740 \\
$€$ & 163 & 55 & -109 & 148 & 0 & -148 \\
(in- and outpatients) & & & & & & \\
\end{tabular}

